\title{
5-FLUOROCITOSINA E ANFOTERICINA-B NO TRATAMENTO DA CRIPTOCOCOSE DO SISTEMA NERVOSO CENTRAL
}

\author{
J. P. S. NOBREGA \\ J. A. Livramento $::$ \\ A. Spina-França $: *:$
}

A maior incidência da criptococose do sistema nervoso central (SNC) verificada atualmente ${ }^{\text {to }}$ tem sido discutida em nosso meio sob vários aspec$\operatorname{tos}^{7,11}$, ressaltando-se aqueles sobre a terapêutica baseada na anfotericina-B ${ }^{3,9}$. Desde 1955 esta droga é a medicação de escolha ${ }^{12}$, mas seu emprego apresenta limitações devidas: a efeitos colaterais, como sua nefrotoxidade; à existência de cepas de Cryptococcus neoformans resistentes à anfotericina-B; à contra-indicação do seu emprego em pacientes com certas nefropatias. Limitaçōes como essas levaram a que fosse tentado o emprego de novos medicamentos, como a 5-fluorocitosina (5-FC), cuja atividade fungicida já foi comprovada em "in vivo" e "in vitro" pelo menos em relação à crypiccocose, candiase ${ }^{1,2,5}$ e cromomicose ${ }^{1,2,5}$.

Em nosso meio, o emprego da $5-\mathrm{FC}$ ainda é incipiente ${ }^{4}$ e o propósito deste estudo é relatar os resultados obtidos mediante o emprego associado de 5-FC e anfotericina-B em dois pacientes com criptococose do SNC, em um deles associada a candidiase.

\section{OBSERVAÇŐES}

CASo 1 - J.D.S.B., 42 anos, sexo masculino, branco, registro H.C. 1.018.262. Paciente admitido em 16-01-1973 por apresentar há cerca de 50 dias cefaléia, de início de média intensidade e localizada principalmente na região occipital. Houve piora progressiva da intensidade da cefaléia e, cerca de 15 dias antes da internação, o paciente começou a apresentar diminuição da acuidade visual e diplopia. Exame clínico - Regular estado geral, afebril, pulso: 90 batimentos/min, pressāo arterial: $130 \times 80 \mathrm{~mm} \mathrm{Hg}$, peso: $80 \mathrm{~kg}$; no restante do exame nada foi constatado de anormal. Exame neurológico - Paciente consciente, apresentando crises de agitação; nada de anormal no exame da motricidade e da sensibilidade; papiledema bilateral; estrabismo congervente por paresia dos retos laterais. Exames complementares - Liquido cefalorraqueano (LCR): vide quadro 1 . Eletrencefalograma: normal (16/1); discreta desorganização difusa da atividade elétrica cerebral (13/2). Radiografia do tórax: normal (18/1); formação tumoral projetando-se no seio cos-

Trabalho da Clínica Neurológica da Faculdade de Medicina da Universidade de São Paulo (Prof. H. M. Canelas): * Médico assistente; ** Médico adido; *** Docente Livre. Apresentado ao VI Congresso Brasileiro de Neurologia, Rio de Janeiro, julho 1974. 


\begin{tabular}{|c|c|c|c|c|c|c|c|}
\hline Data & \multicolumn{2}{|c|}{$\begin{array}{c}\text { Pressão } \\
\text { (em água) }\end{array}$} & $\begin{array}{r}\text { Leucócitos } \\
\text { (por }\end{array}$ & $\begin{array}{l}\text { Leveduras } \\
\left.\mathrm{mm}^{3}\right)\end{array}$ & $\begin{array}{l}\text { Proteinas } \\
\text { (mg }\end{array}$ & $\begin{array}{l}\text { Cloretos } \\
\text { por } 100 \mathrm{ml})\end{array}$ & Glicose \\
\hline $05-02-73$ & & 46 & 127 & 25 & 55 & 691 & 72 \\
\hline $08-02-73$ & + de & 80 & 66 & $*$ & 91 & 672 & 72 \\
\hline $10-02-73$ & + de & 80 & 11 & 45 & 80 & 713 & 102 \\
\hline $13-02-73$ & & 70 & 13 & 24 & 94 & 742 & 82 \\
\hline $16-02-73$ & & 80 & 2,0 & 6 & 100 & 649 & 74 \\
\hline $24-02-73$ & & 53 & 2,0 & 4 & 132 & 661 & 82 \\
\hline $26-02-73$ & + de & 80 & 6,0 & 10 & 126 & 649 & 84 \\
\hline $28-02-73$ & & 64 & 4,0 & 17 & 156 & 684 & 116 \\
\hline $01-03-73$ & & 40 & 2,0 & 28 & 100 & 684 & 142 \\
\hline $02-03-73$ & & & craniect & omia descom & essiva & & \\
\hline $16-03-73$ & & 16 & 5,0 & 52 & 420 & 707 & 139 \\
\hline $19-03-73$ & & 15 & 8,0 & 46 & 290 & 684 & 144 \\
\hline $21-03-73$ & & & 346 & 43 & 250 & 725 & 126 \\
\hline $26-03-73$ & & 22 & 11 & 13 & 500 & 713 & 163 \\
\hline $30-03-73$ & & 40 & 2,0 & 19 & 660 & 672 & 300 \\
\hline 04-04-73 & & 14 & 4,0 & $*$ & 660 & 713 & 300 \\
\hline $11-04-73$ & & 23 & 1,0 & 30 & 640 & 707 & 262 \\
\hline $12-04-73$ & & & derivaçã & ventriculo- & ritoneal & & \\
\hline $17-04-73$ & & 12 & 1,7 & 120 & 260 & 701 & 158 \\
\hline $21-05-73$ & & 16 & 15 & $*$ & 384 & 729 & 28 \\
\hline
\end{tabular}

Quadro 1 - Liquido cefalorraqueano (punçoes lombares, pacientes em decúbito lateral) no caso 1. Legenda: para pressão inicial, + de 80 refere-se $a$ valores acima de $80 \mathrm{~cm} / a ́ g u a ; ~ p a r a ~ l e v e d u r a s$ (identificadas em todas as amostras como Cryptococcus neoformans), * corresponde a presentes mas em número não contado.

to-frēnico direito, sugestiva de toruloma (15/3). Carótido-angiografia: normal (15/2 e 1/3); sinais indiretos de dilatação ventricular (10/4). Pneumoventriculografia: ventriculos laterais sem anormalidades $(2 / 3)$.

O diagnóstico de meningo-encefalite por criptococos foi firmado por ocasiāo da internação e mediante o exame do LCR, tendo sido iniciado o tratamento com anfotericina-B por via intravenosa e, ulteriormente, por via intrarraqueana também. O controle da hipertensão intracraniana foi tentado, de início, mediante o emprego de digoxina e de diamox e, ulteriormente, mediante cirurgia descompressiva bifrontal. Após esta última houve melhora do quadro de hipertensão intracranina, bem como da acuidade visual. Durante esse ato cirúrgico foi constatada a presença de pequenos abscessos na corticalidade cerebral. Após ele foi iniciada a administração de anfotericina-B por via intraventricular também.

A administração de anfotericina-B intravenosa foi suspensa temporariamente por algumas vezes, devido ao aparecimento de efeitos nefrotóxicos. A administracão intrarraqueana foi suspensa devido a ocorrência de aumento considerável da concentração protêica do LCR; a administração intraventricular foi suspensa quando da instalação de ventriculite aguda, possivelmente por contaminação. Ao todo foram empregados $5.375 \mathrm{mg}$ de anfotericina por via intravenosa e 13,5 $\mathrm{mg}$ por via intrarraquena.

Associada à anfotericina-B, foi utilizada a $5-\mathrm{FC} *$ na dose inicial de $50 \mathrm{mg} / \mathrm{kg} / \mathrm{dia}$ e, posteriormente, de $100 \mathrm{mg} / \mathrm{kg} / \mathrm{dia}$.

* Ancotil, fornecido por Produtos Roche Quimicos e Farmacêuticos S.A. 
Apesar de toda a medicação, repetidos exames de LCR mostraram que nāo estava havendo controle da doença. Nova exacerbação do quadro de hipertensão intracraniana, levou a que fosse instalada derivação ventrículo-peritoneal. Houve controle do processo hipertensivo. Posteriormente, a válvula deixou de funcionar satisfatoriamente e ressurgiu a sintomatologia de hipertensão. Houve piora progressiva das condições gerais do paciente, ocorrendo o óbito em 26-5-1973, 180 dias após o início da doença e 130 dias após o início do tratamento.

Caso 2 - J.N.H.P.N., 33 anos, sexo masculino, branco, Registro H.C. 979.459. Paciente em acompanhamento na Clinica Urológica da mesma Faculdade, na qual foi readmtido em 11-9-1973 por apresentar cefaléia há 10 dias. A cefaléia era frontal, contínua, melhorando de inicio com analgésicos comuns e era acompanliada de febre $\left(38-39^{\circ} \mathrm{C}\right)$. Um dia antes da internação surgiram vômitos, diplopia e episódios de confusão mental. Antecedentes individuais - Há cerca de 2 anos fora constatada hipertensāo arterial, cujo estado levou a que fosse indicado transplante renal. Este foi efetuado em 12-01-1972, 20 dias após nefrectomia bilateral. Houve ulterior normalização da pressão arterial. Desde a ocasião do transplante o paciente passou a ser medicado com Imuran (250 mg/dia) e Meticorten (30 mg/dia). Essa medicação foi mantida até a época da internação, embora em dosagens menores. Exame clínico - Regular estado geral, afebril, pulso: 120 batimentos $/ \mathrm{min}$, pressão arterial: $110 \times 60 \mathrm{~mm} \mathrm{Hg}$, peso: $73 \mathrm{~kg}$; no restante do exame nada foi constatado de anormal. Exame neurológico - Paciente obnubilado; oscilações à estação ereta que não se acentuam ao fechar os olhos; nada de anormal ao cxame da motricidade e da sensibilidade; papiledema bilateral; estrabismo divergente por paresia dos retos internos. Exames complementares - Liquido cefalorraqueano: vide quadro 2. Eletrencefalograma: discreta desorganização difusa associada a anormalidade paroxística também difusa, mas predominando em áreas fronto-temporais (13/9); discreta desorganização difusa da atividade elétrica cerebral (12/10); normal (29/10 e 26/11). Carótido-angiografia normal (14/3). Cintilografia cerebral normal (25/9). Cultura de escarro: Candida albicans (14/9).

Como fora evidenciada, mediante cultura de amostras do LCR $(28 / 9$ e 1/10), a presença de Candida albicans foi estabelecido o diagnóstico de candidiase do SNC, sendo o paciente transferido para a Clínica Neurológica (3-10-1973). Tendo em vista o fato de ter sido o paciente submetido a transplante renal decidiu-se. de inicio, utilizar a anfotericina-B apenas por via intrarraqueana, associada à 5-FC. Esta foi empregada inicialmente na dosagem de $150 \mathrm{mg} / \mathrm{kg} / \mathrm{dia}$ e, ulteriormente, de $200 \mathrm{mg} / \mathrm{kg} /$ dia. Ao mesmo tempo foram mantidos o Imuran ( $100 \mathrm{mg} / \mathrm{dia}$ ) e o Meticorten ( $12,5 \mathrm{mg} / \mathrm{dia})$. Foram empregadas dosagens crescentes de anfotericina-B por via intrarraqueana até quando, com a administração de $1 \mathrm{mg}$, desenvolveu-se quadro de paraparesia crural flácida que regrediu no decorrer de algumas horas, mas que levou a abandonar essa via para ministrar a droga (29-10-1973).

Como novos exames de LCR $(25 / 1 C$ e $5 / 11)$ passaram a revelar a presenca de Cryptococcus neoformans, resolveu-se associar à 5-FC a anfotericina-B por via intravenosa, mantendo-se controle rigoroso da função renal. Não houve qualquer intercorrência e a administração intravenosa de anfotericina-B foi mantida até completar-se a dose de $2 \mathrm{~g}$ (1-2-1974). A 5-FC na dosagem de $200 \mathrm{mg} / \mathrm{kg} / \mathrm{dia}$ foi mantida até a completa normalização do LCR (18-4-1974), cerca de 30 dias após o inicio da sintomatologia e de 200 dias de tratamento por essa droga. Controles periódicos clinicos e do LCR foram mantidos até janeiro de 1975.

\section{COMENTARIOS}

Embora a anfotericina-B seja a medicação de escolha para o tratamento da criptococose do SNC, a já elevada percentagem de insucessos registrados, levou ao uso da $5-\mathrm{FC}^{13}, 14,15,16$. 


\begin{tabular}{|c|c|c|c|c|c|c|}
\hline Data & Colheita & $\begin{array}{c}\text { Pressão } \\
(\mathrm{cm} \text { água) }\end{array}$ & $\begin{array}{l}\text { Leucócitos } \\
\text { (por } \mathrm{mm}^{3} \text { ) }\end{array}$ & $\begin{array}{r}\text { Proteinas } \\
\text { (em }\end{array}$ & $\begin{array}{c}\text { Cloretos } \\
\mathrm{mg} \text { por } 100\end{array}$ & ml) \\
\hline $12-09-73$ & SOD & 38 & 133 & 75 & 707 & 50 \\
\hline $20-09-73$ & SOD & 29 & 23 & 40 & 665 & 70 \\
\hline $26-09-73$ & SOD & 25 & 28 & 50 & 649 & 52 \\
\hline $05-10-73$ & LD & & 48 & 67 & 665 & 46 \\
\hline $10-10-73$ & LD & & 38 & 47 & 750 & 50 \\
\hline $15-10-73$ & LD & & 80 & 360 & 707 & 108 \\
\hline $25-10-73$ & LD & 0 & $25 *$ & 34 & 662 & 69 \\
\hline $05-11-73$ & LD & 6 & $15 *$ & 36 & 705 & 52 \\
\hline $08-11-73$ & LD & 30 & 10 & 41 & 720 & 58 \\
\hline $23-11-73$ & LD & & 41 & 42 & 685 & 58 \\
\hline $30-11-73$ & LD & 26 & 14 & 41 & 705 & 60 \\
\hline $14-12-73$ & LD & 15 & 16 & 40 & 720 & 65 \\
\hline $03-01-74$ & LD & 24 & 16 & 32 & 676 & 72 \\
\hline $21-01-74$ & SOD & 15 & 5 & 22 & 676 & 64 \\
\hline $07-02-74$ & SOD & & 1,7 & 23 & 760 & 72 \\
\hline $14-02-74$ & SOD & & 10 & 23 & 745 & 53 \\
\hline $07-03-74$ & SOD & & 5 & 21 & 725 & 62 \\
\hline $18-04-74$ & SOD & 17 & 2.7 & 20 & 722 & 55 \\
\hline 21-05-74 & SOD & & 3.0 & 19 & 687 & 64 \\
\hline $27-06-74$ & SOD & & 3,0 & 20 & 702 & 63 \\
\hline $18-10-74$ & SOD & & 2.0 & 11 & 702 & 58 \\
\hline $30-01-75$ & SOD & & 0,7 & 17 & 702 & 68 \\
\hline
\end{tabular}

Quadro 2 - Liquido cefalorraqueano no caso 2. Legenda: para colheita, SOD punçũo sub-occipital com o paciente em decúbito lateral e LD - punsio lombar com o paciente em decúbito lateral; para leveluras (identificadas como Cryptococcus neoformans); $*$ corresponde a presentes. em número inferior a $1,0 \mathrm{~mm}^{3}$.

A 5-FC é uma pirimidina fluorinada, quimicamente relacionada ao 5-fluoro.uracil (5-FU). Sua atividade é, em primeiro lugar, fungostática, tornando-se fungicida na medida em que o tratamento é suficientemente prolongado. Seu modo de ação parece estar relacionado à capacidade que têm certos fungos de deaminar a 5-FC em seu citoplasma, transformando-a em ว-FU. O 5-FU recém-formado interfere na sintese do DNA, pode ser incorporado ao RNA - formando um falso RNA mensageiro - e, possivelmente, um RNA deficiente. Assim sendo, a eficácia da droga parece estar na dependência da respectiva concentração intracelular.

As concentrações médias nos diversos tecidos, inclusive no parênquima nervoso e no LCR se assemelham às do sangue. Isto contrasta com o que se observa em relação à anfotericina-B: a concentração no LCR é cerca de $1 / 40$ daquela observada no sangue.

A dose diária de 5-FC a ser ministrada por via oral é de 100 a 200 $\mathrm{mg} / \mathrm{kg}$ de peso, subdividida em 4 tomadas. A duração do tratamento é variável, estando na dependência da gravidade da doença. Para a criptococose do SNC é recomendada a dose de $200 \mathrm{mg} / \mathrm{kg} /$ dia por um mínimo de 4 meses. Como efeitos colaterais do uso da 5 -FC são citadas alterações da crase san- 
guinea e de funções hepáticas, bem como a ocorrência de náuseas, vômitos, diarréia, exantemas e, menos comumente, confusão mental, alucinações, cefaléia e vertigens. Em pacientes com comprometimento da função renal, a 5-FC deve ser administrada com cautela, por ser eliminada principalmente pelos rins e sem ser metabolizada. O comprometimento renal pode, portanto, levar a acúmulo da droga no organismo. Por outro lado, considera-se a vigência de comprometimento hepático severo a contra-indicação principal para o tratamento com 5-FC.

A 5-FC pode ser mais eficaz se utilizada juntamente com pequenas quantidades de anfotericina- $B$, contra fungos relativamente resistentes a cada um desses agentes quando utilizado em separado. $O$ sinergismo da anfotericina-B e da 5-FC resulta provavelmente de alteração na permeabilidade da membrana da superfície do fungo, possibilitando maior penetração da droga ${ }^{6}$.

Os dois casos relatados colocam em evidência a diversidade de evolução do quadro clínico frente a um esquema terapêutico semelhante, assim como a impossibilidade de serem previstas as complicações dele decorrentes.

O caso 1 apresentou evolução desfavorável, apesar de todas as medidas terapêuticas adotadas. Ocorreram, durante o tratamento, efeitos colaterais à utilização da anfotericina-B, principalmente quanto à função renal. Esta droga foi utilizada desde o início do tratamento, atingindo-se o total de $5.375 \mathrm{mg}$. Na ausência da resposta inicial esperada pela sua administração intarvenosa, 14 dias depois - isto é, 64 dias após o início da sintomatologia - passou ela a ser administrada por vai intrarraqueana também. Como houvesse boa tolerância à dose inicial de $0,1 \mathrm{mg}$, esta foi aumentada progressivamente até $1,5 \mathrm{mg}$ por aplicação, as quais foram feitas 3 vezes por semana em média e mediante punção lombar. Apesar da administração simultânea da anfotericina-B por via intravenosa e intrarraqueana, o paciente continuava a piorar clinica e laboratorialmente. Foi então introduzida, 114 dias após o início da sintomatologia, a $5-\mathrm{FC}$ em dose inicial de $50 \mathrm{mg} / \mathrm{kg} / \mathrm{dia}$, logo aumentada para $100 \mathrm{mg} / \mathrm{kg} /$ dia. Durante 2 meses foi mantida a associação anfotericina-B intravenosa e 5-FC oral, sem que se notasse qualquer resposta terapêutica, vindo o paciente a falecer 180 dias após as manifestações iniciais da doença.

Destaque especial merece o caso 2 pela sua evolução favorável e por tratar-se de paciente submetido a transplante renal, fazendo uso de drogas imunossupressoras e de corticosteróides. Como fora inicialmente comprovada apenas a candidiase do SNC, estabeleceu-se tratamento por 5-FC (150 $\mathrm{mg} / \mathrm{kg} / \mathrm{dia}$ ) associada a anfotericina-B por via intrarraqueana apenas. $\mathrm{O}$ episódio de paraparesia crural relatado levou a abandonar o emprego da anfotericina-B por essa via e a aumentar para $200 \mathrm{mg} / \mathrm{kg} / \mathrm{dia}$ a dose de 5-FC. Apesar da melhora clínica observada, a constatação de Cryptococcus neoformans no LCR levou a que se iniciasse o uso intravenoso da anfotericina-B em associação à 5-FC, apesar dos riscos inerentes ao fato de ter 
sido o paciente submetido a transplante renal prévio. Ao contrário do caso anterior, não foram verificados efeitos colaterais. Como o LCR se apresentasse normal em repetidos exames, a anfotericina-B foi suspensa ao atingir-se a dose total de $2 \mathrm{~g}$. A administração de 5-FC foi mantida por mais 76 dias ainda, após cerca de 6 meses e meio de emprego ininterrupto.

Constata-se, pela análise dos dois casos, a impossibilidade de prever complicações dependentes do uso de cada uma das drogas. Assim, no caso 1, ocorreram efeitos nefrotóxicos da anfotericina-B, ao passo que no caso 2 transplantado renal e imunossuprimido - tais efeitos não foram observados. A evolução desfavorável da doença no caso 1 pode ser atribuída a vários fatores atuando isolada ou conjuntamente, tais como: resistência do fungo à anfotericina-B; baixas doses de 5-FC; resistência do fungo à 5-FC. Esta já foi relatada quando de tratamentos baseados em doses inferiores a 100 $\mathrm{mg} / \mathrm{kg} / \mathrm{dia}^{2}$. Por outro lado, a evolução favorável no caso 2 pode ser relacionada a vários fatores, entre os quais: sensibilidade do fungo às drogas utilizadas; emprego desde o início de dose eficiente de 5-FC; sinergismo de ação da anfotericina-B e 5-FC.

Tais fatos têm importante implicações clínicas, especialmente no que diz respeito ao sinergismo de medicamentos antimicóticos. A ação sinérgica desses medicamentos abre oportunidade para terapêuticas mais efetivas, baseadas no uso de dosagens menores, as quais podem permitir contornar, até ccrto ponto, o problema da toxicidade de cada uma dessas drogas.

\section{RESUMO}

Registro de dois casos de criptococose do sistema nervoso central, em um deles associada a candidíase. Em ambos foram utilizados no tratamento anfotericina-B e 5-fluorocitosina. Em função dos resultados obtidos são feitas considerações quanto à utilidade de cada uma das drogas no tratamento da criptococose, bem como quanto ao uso associado de ambas.

\section{SUMMARY}

\section{Amphotericin-B and 5-fluorocytosine in the treatment of cryptococcosis of the central nervous system: report of two cases}

Two cases of cryptococcosis of the central nervous system are reported. The treatment was based on the association of amphotericin-B with 5-fluorocytosine. Details on the therapeutic proprieties of these drugs are discussed considering the results obtained. Amphotericin-B was administered intravenously and intrathecally in the two cases.

The total amount of amphotericin administered intravenously in the first case was $5.375 \mathrm{mgm}$, and the oral doses of 5-fluorocytosine were not superior 
to $100 \mathrm{mgm} / \mathrm{kg} /$ of body weight. This patient died 130 days after the first symptoms of the disease.

The second patient had been submitted previously to kidney transplantation after bilateral nephrectomy, and inmunossupressive drugs were administered to him since then. Candidiasis and cryptococcosis of the central nervous system developped two years later. 5-fluorocytosine was administered orally (200 mgm/ $\mathrm{kg}$ of body weight) and amphotericin-B. The total amount of this drug administered intravenously was $2.00 \mathrm{mgm}$. There was complete clinical and laboratory remission of the mycoses in this case.

\section{REFERENCIAS}

1. BEINE. J. P.; LONTIE, M. \& VANDEPITTE, J. - Cryptococcal meningoencephalites and 5-fluorocytosine. Brit. med. J. 5753:107, 1971.

2. FASS, R. J. \& PERKINS, R. L. - 5-fluorocytosine in the treatment of cryptococcal and candida mycoses. Ann. int. Med. 74:535, 1971.

3. GIORGI, D.; REIS, J. B.; PUPO, P. P. \& LIMA, J. G. C. - Tratamento da criptococose do sistema nervoso pela anfotericina-B. Arq. Neuro-Psiquiat. (São Paulo) 17:377, 1959

4. GIORGI, D. R.: REIS, J. B.; BEI, A. \& REIS FILHO, J. B. - Criptococose do sistema nervoso central. Arq. Neuro-Psiquiat. (São Paulo) 32:77, 1974.

5. GONZALEZ OCHOA, A. - Curación de la criptococosis y de la cromomicosis con 5-fluorocitosina. Rev. Invest. Salud Publica (México) 30:63, 1970.

6. MEDOFF, G.; KOBAYASHI, G. S.; KWAN, C. N.; SCHLESSINGER, D. \& VENKOV, P. - Potentiation of rifampicin and 5-fluorocytosine as antifungal antibiotics by amphotericin-B. Proc. nat. Acad. Sci. 69:196, 1972.

7. OLIVEIRA, C. \& ALENCAR, A. - Criptococose do sistema nervoso: apresentaçăo de 2 casos. J. brasil. Neurol. (Rio de Janeiro) 17:93, 1965.

8. SCHOLE, H. J. - Antimykoticum 5-fluorocytosine. Mykosen 13:179, 1970.

9. SGINA-FRANÇA, A. \& SILVA, J. B. - Diagnóstico e tratamento da criptococose do sistema nervoso central. Considerações sobre 16 casos. Arq. Neuro-Psiquiat. (São Paulo) 26:115, 1968.

10. TAY, C. H.; CHEW, W. L. S. \& LIN, L. C. Y. - Cryptococcal meningitis: its apparent increased incidence in the Far East. Brain 95:825, 1972.

11. TOlOSA, A.; LACAZ, C. S. \& SPINA-FRANÇA, A. - Criptococose do sistema nervoso central. Registro de um caso. Arq. Neuro-Psiquiat. (São Paulo) 14: $171,1956$.

12. UTZ, J. P.; DUNA, R. J.; MEGEHEE, R. F. \& WARNER, J. F. - Chemotherapy of the systemic mycoses: recent clinical observations. Vth. Congress Internat. Soc. of Human and Animal Mycology, Paris, 1971, pág. 295.

13. VANDEVEldE, A. G.; MAUVERI, A. A. \& JOHNSON, J. E. - 5-fluorocytosine in the treatment of mycotic infections. Ann. int. Med. 77:43, 1972.

14. Editorial - Flucytosine (Ancobon): a new antifungal drug. The Medical Letter on Drugs and Therapeutics 14:29, 1972.

15. Prospecto - The clinical evaluation of Ancobon (flucytosine). Data on rile. Roche Scientific Summary, Nutley, 1971.

16. Prospecto - Data sheet on 5-fluorocytosine. Roche, Nutley, 1972.

Clínica Neurológica - Faculdade de Medicina, Universidade de São Paulo Caixa Postal 3.461 - 01000 São Paulo, SP - Brasil. 